et al, 1998). The prevalence of affective disorders (major depression, dysthymia, mania, hypomania and bipolar disorder) was reported as only $1.7 \%$ among those aged 65 years and over, while it was $5.8 \%$ among the total adult population. Because mental disorders were reported in this survey to have a much higher prevalence among young people (over $20 \%$ at age 18 44 years, compared with $6.1 \%$ after age 65 years), the Minister for Health emphasised the need for a national focus on mental health services for young people. The New South Wales Department of Health referred to the same survey and commented on the lower mental health morbidity of older people, in a document describing plans for the distribution of resources.

Survey reports can be misinterpreted. Clinicians and administrators may need to be reminded that treatment for depression may be of benefit to far more older people than just those with a diagnosis of major depression. In this context, I agree that some prevalence studies should be recognised (at least by budget-holders) as "not that interesting".

Blazer, D. (1999) EURODEP Consortium and late-life depression. British joumal of Psychiatry. 174, 284-285.

Copeland, J. R. M. (1999) Depression of older age. Origins of the study. British journal of Psychiotry 174. 304-306.

McLonnan, W. (1998) Mental Health and Wellbeing: Profile of Adults, Austrolia 1997. Canberra: Australian Bureau of Statistics.

Reifler, B.V. (1994) Depression: diagnosis and comorbidity. In Diagnosis and Treotment of Depression in Late Life (eds L. S. Schneider, O. F. Reynolds, B. D. Lebowitz, et of). pp. 55-59. Washington, DC: American Psychiatric Press.

Snoundon, J., Draper, B., Chil, E., ef al (1998) Surveys of mental health and wellbeing: critical comments. Australasion Psychiatry 6, 246-247.

J. Snowdon Department of Psychological Medicine, University of Sydney, Rozelle Hospital, NSW 2039, Australia

\section{Stereotypes of ageing}

Sir: Copeland et al (1999) concluded that depressive symptoms in older people do not uphold the stereotypes of old age. However, the study itself seems to preconceive the stereotype that 'older people are asexual'. This is contrary to the evidence that sex continues to play an important part in the lives of both men and women, at least until the mid-seventies, with little if any decline in enjoyment and satisfaction (Kinsey et al, 1953; Kellett, 1996). Sexual dysfunc- tion is well recognised as a symptom of depression in the ICD-10 and in the DSM-IV as well as in community studies of the depressed elderly (Kivela \& Pahkala, 1988). We regret to note that the new EURO-D scale (Prince et al, 1999) also accepts this stereotype by ignoring sexual dysfunction as a symptom of depression in the elderly.

\section{Copeland, J. R. M., Beekman, A. T. F., Dewes M. E. *t of (I999) Cross-cultural comparison of depressive symptoms in Europe does not support stereotypes of ageing. British journal of Psychiatry. 174, 322-329. \\ Kellett, J. M. (1996) Sex and the elderly male. Sexual} and Morital Theropy, II, 281-288.

Kinaer, A. C., Pomeroy, W. B., Martin, C. E., of of (1953) Sexual Behoviour in the Human Female. Philadelphia, PA: W. B. Saunders.

Khrele, S. I. \& Pahlobla, K. (1982) Clinician-rated symptoms and signs of depression in aged Finns. International journal of Social Psychiatry, 4, 274-284.

Prince, M. J., Relschles, F., Beelaman, A.T. F., ef of (1999) Development of the EURO-D scale - a European Union initiative to compare symptoms of depression in 14 European centres. British journal of Psychiatry, 174, 330-338.

A. Praseedom, P. A. Tube, A. Vourdas, B. Rafnar, M. Woodfield Department of Psychiatry. West Suffolk Hospital, Bury St Edmunds IP332QZ

Author's reply: I will start by trying to answer the last point raised by Drs Praseedom, Tube, Vourdas, Rafnar and Woodfield. The purpose of the EURO-D Scale is to harmonise some existing scales of depression. Rightly or wrongly, such scales for older people tend not to include a question about sexual activity, which is why EURO-D itself could not include it. Similarly, the fact that sexual activity was not discussed in the article should not be interpreted to mean that the authors do not regard it as important in older people. The items discussed were limited to those which had been recorded by sufficient centres to make comparison possible. Sexual activity was not one of these. In a longitudinal study in which it is proposed to burden the respondent with later interviews, the great fear of research workers is that of refusal to proceed after the first interview. Questions on sexual activity were removed from the community versions of the Geriatric Mental State when it was found to upset a small proportion of respondents. They can be included if wished. Also, although intrinsically interesting, it is not a symptom essential for diagnosis.

J. R. M. Copeland University Department of Psychiatry, Royal Liverpool University Hospital, Liverpool L69 3GA

\section{Old age forensic psychiatry}

Sir: The editorial by Yorston (1999), while thought-provoking in that it highlights the potential creation of a sub-speciality, is not backed by robust arguments. Simply quoting that crime is rarely associated with the elderly is not an argument in favour of creating a sub-speciality within forensic psychiatry. In our experience, there is enough evidence to support the view that resources, if available, should be concentrated on other subgroups of patients (i.e. young offenders, women) among whom there is a well-established lack of resources to meet an increasing demand.

The author seeks to create an impression of a distinct lack of inter-speciality collaboration in respect of forensic psychiatry issues pertaining to the elderly. This surprises us as it has not been our experience, certainly at local level. When appropriate, there is close and open communication between the old age and regional forensic psychiatry services. This inter-speciality collaboration helps to identify potential problems and allows for little delay when intervention is required to respond and manage such cases as they present, particularly in the community. This has, in the past, allowed for ease of passage through the medium secure unit.

One might consider that medium secure units are not ideal environments to meet the needs of the elderly, but to extend this, as the author suggests, to a declaration of unmet needs is too sweeping a statement.

From a training viewpoint, we would expect those in higher forensic training to have appropriate experience, in both assessing and treating elderly offenders. Current higher training programmes in forensic psychiatry should offer experience in sub-specialities such as child and adolescent, learning disability, drug and alcohol, prison, and old age psychiatry.

To conclude, the notion that elderly offenders are missing out in terms of specialist assessment and treatment does not, we believe, hold true.

Yorntom, G. (1999) Aged and dangerous. Old age forensic psychiatry. British journol of Psychiotry, 174, 193-195.

1. Gairin, P. Quinn The Yorkshire Centre for Forensic Psychiatry, Ouchthorpe Lane, Wakefield, West Yorkshire WFI 3SP

\section{Cytosolic phospholipase $A_{2}$ gene in schizophrenia}

Sir: Walker et al (1999) present an excellent, and much needed, overview of altered lipid 